\title{
Sports utility vehicle seat structure simulation of frontal oblique crash
}

\section{Sutartip Wittayapiyanon ${ }^{1 *}$, Sathaporn Chuepeng ${ }^{2}$}

\author{
1, 2 Department of Mechanical Engineering, Kasetsart University, Sriracha Campus, Chonburi, Thailand
}

\author{
Index Terms \\ Backrest \\ Explicit Dynamic \\ Finite Element Method \\ Oblique Crash \\ Seat \\ Simulation \\ SUV
}

Received: 26 December 2016

Accepted: 2 February 2017

Published: 30 June 2017

\begin{abstract}
The seat structure of the Sports Utility Vehicle (SUV) has gained more attention in developing lightweight design using available materials different in grades and their strengths. The SUV industry has drastically shown an incessant growth in the present. By this scenario, safety issues are of interest mainly for the users. This work, therefore, simulates and analyzes an SUV's seat for stress distribution and deformation of its structure using finite element method. The seat is situated in the SUV where it is crashed in the front by oblique angle from 0 degree to 15 degrees adjacent to the straight direction in both right and left sides. This type of collision is considered to be an accident of vehicle resulting in serious injuries. The analysis employs an explicit dynamic simulation during the real frontal impact and includes a direct contact of Asia-EvaRID (ER) model with the backrest. Under the test by simulation conforming to the industrial standards, ECE standards in particular, the seat structure parts of the backrest relative to the sled were measured in displacement of deformation with a minimum interval time of accident, for the velocity ranging from $60 \mathrm{~km} / \mathrm{h}$ to $100 \mathrm{~km} / \mathrm{h}$. The results have explored that the seat structure withstanding the stress distribution and deformation under static load evaluation testing was affected by vehicle velocity and crash direction in an accident. The analysis of the left and right side impact when fastened seat belt generated the maximum stress in the direction of 12.85 degrees head and 6.04 degrees chest from the lateral axis and 4.28 degrees head and 2.01 degrees chest from the lateral axis, respectively. The unfastened seat belt case has shown the maximum distribution at 9 degrees head and degree chest directions over the peak time.
\end{abstract}

(C) 2017 The Author(s). Published by TAF Publishing.

\section{INTRODUCTION}

SUV is a seven-seat light-duty truck with large estate carrying space of a minivan or large sedan. Seat comfort is primarily important when it has gained more recognition while the sale market of the SUV becomes larger. However, the issue of safety in transport has been enlarged for attention to people who are occupying the SUVs throughout the world.

The SUV seat structures under oblique frontal crash have been found to be globally important especially for the seatback and head, as by "the uniform provisions concerning the approval of vehicles with regard to the seats [1]". The industry standards: "ECE Regulation No. 17 mainly examines head restraint [1]" while "JAMA [2]", "FMVESS No. 208, and NHTSA $[3,4]$ " measure the crash worthiness of pas- senger vehicle and specify performance requirements for protection of vehicle occupants in crashes. In general manufacturing process of the SUV seat structures, design and material in terms of strength, durability, and reliability for each single model are different. In addition, average vehicle SUV weight can vary significantly by the model and even the model year of a car.

The main aim of this research work is to analyze the SUV's seat structure in frontal overlap collinear car-to-car crash at the velocity ranging from $60 \mathrm{~km} / \mathrm{h}$ to $100 \mathrm{~km} / \mathrm{h}$, within the 20 degrees side-by-side cushion. The comparison between fastened and unfastened seat belt conditions, and the backrest lock have been examined. The seat model is analyzed using an explicit dynamic simulation and the commercial software package ANSYS. The simulation con-

* Corresponding author: Sutartip Wittayapiyanon

${ }^{\dagger}$ Email: sutartip@eng.src.ku.ac.th 
ditions are an oblique impact from both in the right and left hands under speed variation. Deformation and stress distribution from the simulation conditions and the subsequent evaluation under the industrial standard are incorporated, related to safety test. In the end, the simulated results have been compared and discussed with those by simulation and experiment obtained from the literature.

\section{LITERATURE REVIEW}

The standard reference for the head restraints by the E/ECE/324 regulation No.17 [1] is to limit the rearward displacement of an adult occupant's head in relation to his torso to reduce injury of the cervical vertebrae in the event of an accident. For head restraints not adjustable for height, the height shall be not less than $800 \mathrm{~mm}$ in the case of front and acceleration applies of not less than $20 \mathrm{~g}$ [1]. In addition, the standard reference of JAMA [2] on the appropriate static height of head restraint was accomplished using the BioRID model. JAMA examined these hypotheses with an actual car seat in rear effect experiments. The head restraint height equivalent passenger is considered to be in the range of 800 to $850 \mathrm{~mm}$ or higher that might affect [2].

In terms of real case scenarios, the reference of research in the Federal Motor Vehicle Safety Standard (FMVSS) No. 208 barrier test and the National Automotive Sampling System (NASS) [3] requires impact speeds up to $48 \mathrm{~km} / \mathrm{h}$, including crash modes to characterize the frontal crash and full barrier or oblique frontal impacts [3]. For side impact, the research protocols in the National Highway Traffic Safety Administration (NHTSA) oblique crash tests were performed in both the left and right side impact conditions. The speeds of vehicle crash were applied from 56 $\mathrm{km} / \mathrm{h}$ to $113 \mathrm{~km} / \mathrm{h}$ at a 15 -degree angle, and 35 to 50 percent overlap. For the test model in this scheme, a THOR 50th percentile male Anthropomorphic Test Device (ATD) is seated for both the driver's and front passenger's positions [4]. [5] analyzed two van seat models using an explicit dynamic simulation for high-velocity frontal impact, starting from $50 \mathrm{~km} / \mathrm{h}$ to $80 \mathrm{~km} / \mathrm{h}$ at $0.0193 \mathrm{~ms}$ time for the crash condition. In the analysis of the EvaRID and BioRID models, deformation and stress distribution of the seats were determined in three dimensions. Meanwhile, the relationship between the measured data and design specifications of the "H" point and the "R" point is the value of the torso angle [6]. In addition, there was a relationship between body mass index and diabetes depending on age, sex, and region reported in [7]. An ATD was used to predict the drivers' behavioral differences before frontal collisions affect the grav- ity of injuries suffered by the occupant as reported in [8]. The test condition was that the pre-crash sled was running at the speed of $67 \mathrm{~km} / \mathrm{h}$, at 0.873 seconds, the sled collided at the speed of $48 \mathrm{~km} / \mathrm{h}$. The kinematics of the THOR dummy were analyzed using finite element method under applied load for two seatbelt types [9]. The subsequent results were the data for the dummy kinematics in the real oblique crash loading condition. Meanwhile, the Global Human Body Model [10] used 3D kinematics data from a series of post-mortem human to test for far-side sled. The test conditions were two low-severities with and without seatbelt, and one high-severity for oblique and lateral impact directions [10]. An investigation on the effects of incorporating a belt-integrated airbag ("airbelt") into a rear seat occupant restraint system has been revealed by [11], at $29 \mathrm{~km} / \mathrm{h}$ and $48 \mathrm{~km} / \mathrm{h}$ speed tests. Frontal impact sled tests were performed with a Hybrid III 50th percentile male anthropomorphic test in the right-rear passenger position of a sedan buck [11]. In the seat design for the BioRID dummy, the controlled displacement and the seat deformation in combination with support for the whole spine have been explored either at 15 or $25 \mathrm{~km} / \mathrm{h}$ [12]. Furthermore, an automotive seat underside impact crash of dynamically validating a typical finite element seat model was used in the virtual development of side impact protection systems [13]. The deformation after the test and differences in the behavior of middle cross member of the backrest are compared.

\section{METHOD}

\section{A. Sports Utility Vehicle Model}

The three-dimensional seat structure model of an SUV manufacturer sold in the market is shown in Fig. 1 with a concise dimension.

\section{B. Reference Data: Characteristics of Body Weight for Seating Positions}

The following characteristics of body weight data in Table 1 were applied to frontal oblique impact in left or right crash direction. The mass data for each body segment was estimated based on stature, weight and average size for the position load test [5]. In this work, the calculation of the mass and mass averaged for each body segment from the mass distribution were in the percentage of the EvaRID and BioRID models [6] for Asian men depending on the application: 4 types of the seat height in each model. 


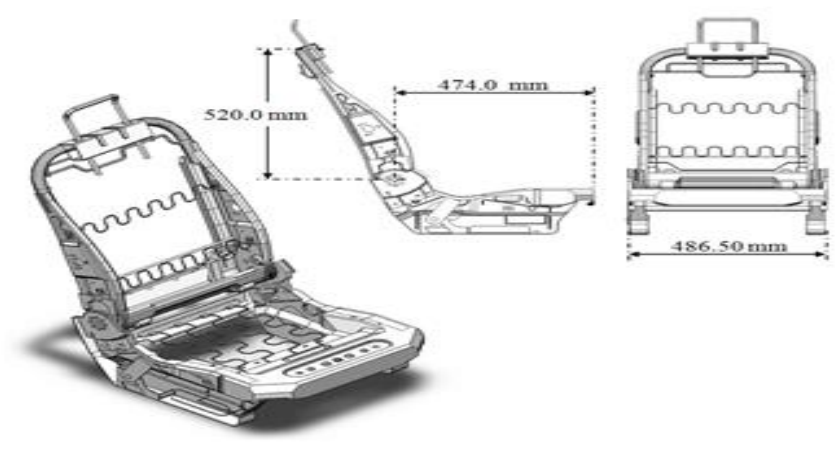

Fig. 1. The 3D seat structure model of SUV manufacturers sold in the market

TABLE 1

MALE'S BODY M(ASS OF ASIA-EVARID AND BIORID MODELS

\begin{tabular}{|c|c|c|c|c|c|c|}
\hline \multirow[t]{2}{*}{ Description } & \multirow[t]{2}{*}{ Models } & \multicolumn{4}{|c|}{ Male Body Mass (kg) } & \multirow[t]{2}{*}{ Average (\%) } \\
\hline & & $171.36 \mathrm{~cm}$ & $170.98 \mathrm{~cm}$ & $169.49 \mathrm{~cm}$ & $168.17 \mathrm{~cm}$ & \\
\hline \multirow[t]{2}{*}{ Head } & EvaRID & 3.67 & 4.01 & 4.05 & 4.06 & 5.71 \\
\hline & BioRID & 3.70 & 4.04 & 4.09 & 4.09 & 5.76 \\
\hline \multirow[t]{2}{*}{ Chest } & EvaRID & 20.17 & 22.05 & 22.30 & 22.31 & 31.40 \\
\hline & BioRID & 21.79 & 23.81 & 24.08 & 24.10 & 33.91 \\
\hline \multirow[t]{2}{*}{ Pelvis } & EvaRID & 16.32 & 17.83 & 18.04 & 18.05 & 25.40 \\
\hline & BioRID & 12.96 & 14.16 & 14.32 & 14.33 & 20.17 \\
\hline \multirow[t]{2}{*}{ Upper arms } & EvaRID & 2.85 & 3.12 & 3.15 & 3.15 & 2.22 \\
\hline & BioRID & 3.29 & 3.59 & 3.63 & 3.64 & 2.56 \\
\hline \multirow[t]{2}{*}{ Lower arms } & EvaRID & 2.45 & 2.68 & 2.71 & 2.71 & 1.91 \\
\hline & BioRID & 3.67 & 4.02 & 4.06 & 4.06 & 2.86 \\
\hline \multirow[t]{2}{*}{ Upper legs } & EvaRID & 11.71 & 12.79 & 12.94 & 12.95 & 9.11 \\
\hline & BioRID & 9.85 & 10.77 & 10.89 & 10.90 & 7.67 \\
\hline \multirow[t]{2}{*}{ Lower legs } & EvaRID & 7.07 & 7.73 & 7.82 & 7.82 & 5.50 \\
\hline & BioRID & 8.98 & 9.82 & 9.93 & 9.94 & 6.99 \\
\hline \multirow[t]{2}{*}{ Total mass } & EvaRID & 64.25 & 70.22 & 71.01 & 71.07 & 100 \\
\hline & BioRID & 64.25 & 70.22 & 71.01 & 71.07 & 100 \\
\hline
\end{tabular}

These stature data in Table 1 and weight of body parts were averaged for Asian male adult and Body Mass Index (BMI) from the Asia-Pacific Perspective Redefining Obesity [7]. In this research, the analyzed data defined the mass distribution of $70.22 \mathrm{~kg}$ and derived by the EvaRID model.

\section{Reference Data: Acceleration for Fastened and Un- fastened Seat Belt}

From the National Highway Traffic Safety Administration (NHTSA) oblique crash test protocol, the moving deformation barrier to vehicle crash has the average mass $1,497 \mathrm{~kg}$ and the target vehicle speed of $113 \mathrm{~km} / \mathrm{h}$ with $15^{\circ}$ angle and 50\% overlap. In addition, for the mass of 2,486 $\mathrm{kg}$ and the vehicle speed of $90 \mathrm{~km} / \mathrm{h}$, the $15^{\circ}$ angle and $35 \%$ overlap were used [3-4]. In this work, the average weight of $1,620 \mathrm{~kg}$ impacted to a stationary vehicle with the speed range between $60 \mathrm{~km} / \mathrm{h}$ and $100 \mathrm{~km} / \mathrm{h}$, and the $0^{\circ}$ to $15^{\circ}$ angles.

In the case of acceleration for fastened seat belt, pelvis, chest and head deflections were also used to predict the chest injury for the male occupant. The analysis for standard seat belt system is to run at $47 \mathrm{~km} / \mathrm{h}$ with the new 
center of gravity (CG) for chest acceleration of $39 \pm 0.4 \mathrm{~g}$ and head acceleration $64 \pm 2.5 \mathrm{~g}$ [8].

In the case of acceleration for unfastened seat belt, the NHTSA conducted the test at $40 \%$ overlap and the measurement acceleration was by $53.2 \mathrm{~g}$ of the oblique impact at $47 \mathrm{~km} / \mathrm{h}$ velocity [3-4]. In addition, the National Automotive Sampling System (NASS) data of the measurement acceleration were by $60 \mathrm{~g}$ at $60 \mathrm{~km} / \mathrm{h}$, and the oblique test vehicles produced intrusion greater than $150 \mathrm{~cm} \mathrm{[4].} \mathrm{By}$ comparing between NHTSA and NASS data, the $67.50 \mathrm{~g}$ acceleration with "the starting velocity of $60 \mathrm{~km} / \mathrm{h}$ is applied to this work for chest deflection, and 108g acceleration for head deflection [7]".

\section{Reference Data: Speed Analysis of the Impact}

The quasi-static scheme resulting in partial or complete failure of the seat backrest across the base of the headrest under acceleration load test is more than $20 \mathrm{~g}$ acceleration according to the Industrial Standard ECE [1] and so on. A high-speed test was the oblique crash in this research starting from $60 \mathrm{~km} / \mathrm{h}$ to $100 \mathrm{~km} / \mathrm{h}$ for the crash condition of the $1,620 \mathrm{~kg}$ weight SUV that was loaded by the acceleration for the whole body.

\section{E. Reference Data: Speed Analysis of the Impact}

The quasi-static scheme resulting in partial or complete failure of the seat backrest across the base of the headrest under acceleration load test is more than $20 \mathrm{~g}$ acceleration according to the Industrial Standard ECE [1] and so on. A high-speed test was the oblique crash in this research starting from $60 \mathrm{~km} / \mathrm{h}$ to $100 \mathrm{~km} / \mathrm{h}$ for the crash condition of the $1,620 \mathrm{~kg}$ weight SUV that was loaded by the acceleration for the whole body.

TABLE 2

VELOCITY AND ACCELERATION DATA IN REAL TIME FOR THE SIMULATION OF FASTENED AND UNFASTENED SEAT BELT

\begin{tabular}{|c|c|c|c|}
\hline \multicolumn{2}{|c|}{ Velocity } & \multirow{2}{*}{$\begin{array}{l}\begin{array}{l}\text { Acceleration } \\
(\mathrm{m} / \mathrm{s} 2)\end{array} \\
\end{array}$} & \multirow{2}{*}{$\begin{array}{l}\text { Time Interval } \\
\text { (s) }\end{array}$} \\
\hline$(\mathrm{km} / \mathrm{h})$ & $(\mathrm{m} / \mathrm{s})$ & & \\
\hline 60 & $16.67[5]$ & 3964 & $0.873[8]$ \\
\hline 80 & $22.22[5]$ & & \\
\hline 100 & $27.78[5]$ & & \\
\hline
\end{tabular}

In Table 2, the model was applied by impact loads to determine head and chest deflection conforming ECE acceleration tests; the input data for acceleration were for fastened and unfastened seat belt, and the time interval [8]. The dummy for the oblique frontal crash determined the angle under the corresponding crash velocity from the positions of each reference target. By this manner, it shows the reference dimension of a new Center of Gravity (CG) of stature deflection in the axial plane and angular displacement for directions of force.

\section{F. Reference Data: New Center of Gravity of Stature De- flection in Axial Plane}

For the fastened seat belt case (Belted), the predicted and measured kinematics for the occupant in the reference and split buckle configurations were observed and collected in Mathematical THOR model evaluation in the oblique near side impacts [9]. The Mathematical THOR model was used to find the new CG of the pelvis and head deflections in $\mathrm{x}$, $\mathrm{y}$ and $\mathrm{z}$ displacements, at $15^{\circ}$ oblique impact and $35 \mathrm{~km} / \mathrm{h}$ velocity.

For the unfastened seat belt case (Unbelted), the predicted standard posture of the Anthropomorphic Test Dummy (SB Scenario) focused on head and chest deflections in $\mathrm{x}$ - and $\mathrm{y}$-axis displacements for the sled frontal collision against the barrier [8] evaluated at the speed of $45 \mathrm{~km} / \mathrm{h}$ with and without braking. The running speeds of the sled were decelerated from $48 \mathrm{~km} / \mathrm{h}$ to $67 \mathrm{~km} / \mathrm{h}$ by breaking, and the sled collides against the barriers.

TABLE 3

NEW CG COORDINATES FROM THE MEASURED REFERENCE DATA

\begin{tabular}{|c|c|c|c|c|c|}
\hline New CG & & Dummy CG Coord & inates & & \\
\hline & Body & $\mathrm{x}_{i}$ & $\mathrm{y}_{j}$ & $\mathrm{k}_{z}$ & Angle \\
\hline Head, belted & $\mathrm{THOR}^{[8]}$ & $180^{[8]}$ & $270^{[8]}$ & $188^{[8]}$ & $21.42^{\circ}$ \\
\hline Pelvis, belted & $75^{[8]}$ & $80^{[8]}$ & $20^{[8]}$ & $12.24^{\circ}$ & \\
\hline $\begin{array}{l}\text { Chest, belted } \\
\text { Head, unbelted }\end{array}$ & & $\begin{array}{l}\text { Pelvis to Chest, } 11.25^{\circ} \text { Approx. } \\
\text { Head to Chest, } 15^{\circ} \text { Approx. }\end{array}$ & & & \\
\hline Pelvis, unbelted & $\begin{array}{l}\text { SB } 100 \\
\text { Scenario }\end{array}$ & $+20 \%{ }^{[8]}$ & $\begin{array}{l}15.5315^{\circ} \text { Approx. } \\
+20 \%[8]\end{array}$ & & \\
\hline Chest, unbelted & $\begin{array}{l}\text { SB } \\
\text { Scenario }^{[8]}\end{array}$ & $\begin{array}{l}216 \\
+20 \%[8]\end{array}$ & $\begin{array}{l}158.50 \\
+20 \%[8]\end{array}$ & $15^{\circ}$ Approx. & \\
\hline
\end{tabular}

Table 3 shows in the first three belted cases for the new CGs obtained from the Mathematical THOR for head and the pelvis directions at $15^{\circ}$ crash obliquities. For the new CG of the chest direction, the approximation in z-axis displacement at $15^{\circ}$ of pelvis deflection and then the new CG of chest would be in $\mathrm{x}-, \mathrm{y}$ - and $\mathrm{z}$-axis displacement. The CG direction effect of oblique impact reference is depicted in Fig. 2. In addition, TABLE 3 also shows the last three unbelted cases for direction at the new stature after the crash.

In Fig. 2, the Asia-EvaRID analyzed the new CG direction for fastened seat belt case affected by the frontal 
oblique impact of SUV's seat structure in single each axis displacements. The H-point to seat end was employed to re-check the seat base from the parameter of bio-fidelity of the Global Human Body Model Consortium 50th percentile male occupant model (GHBMC AM-0) [10]. The GHBMC AM-O occupant model suggested the analysis of whole body kinematic behavior of a $60^{\circ}$ oblique impact. In addition, the Asia-EvaRID used a body kinematic behavior in the position between 81 to $133 \mathrm{~mm}$ of $\mathrm{H}$-point to seat end.

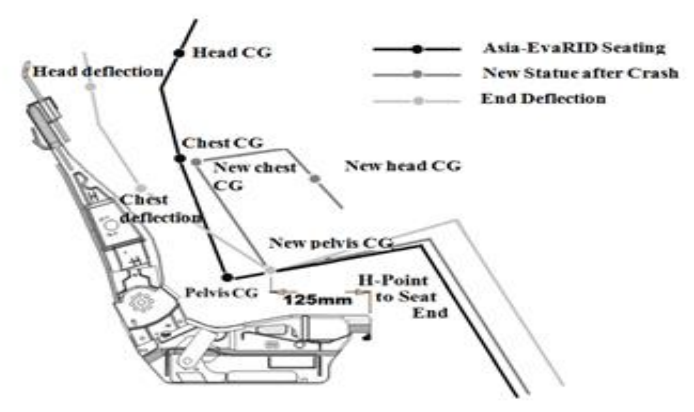

Fig. 2. The 2D-seat structure and Asia-EvaRID model, the new CG direction for fastened seat belt (Belted) as oblique impact on SUV's seat structure, and H-point to seat end

For the unfastened seat belt case, the new CG coordinates were obtained from the SB Scenario (Case III) [8] for the chest direction in $\mathrm{x}$ - and $\mathrm{y}$-axis displacements, at $15^{\circ}$. The new CG of head direction was also found regarding the Asia-EvaRID stature at $15^{\circ}$. The direction affected by frontal impact is shown in Fig. 3.

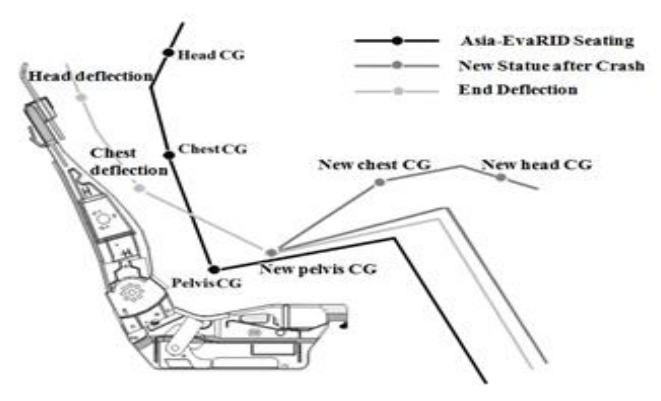

Fig. 3. The 2D seat structure and Asia-EvaRID model, the new CG direction for unfastened seat belt (Unbelted) as oblique impact on SUV's seat structure, and H-point to seat end
In Fig. 3, the Asia-EvaRID results showing the new CG coordinates for unfastened seat belt case were affected by $15^{\circ}$ oblique impact on SUV's seat structure in $\mathrm{x}$ and y-axis displacement. The displacement in z-axis was approximated by $15^{\circ}$.

\section{G. Reference Data: Angular Displacement by Side Force}

The oblique left side impact test for the cases of fastened and unfastened seat belt resulted in angular displacement by force acting under a stature of Asia-EvaRID model. The angular displacements of the head CG and chest CG are proportional to the force action with the time interval, and acceleration of a rigid mass. The data from a rear test in the case of frontal impacts conform to the following characteristics of seating CG displacements. In terms of angular displacements for fastened seat belt during the left side impact, the new belted head CG was measured for displacement for both reference and split buckle scale configurations. Meanwhile, the new belted chest CG displacement was predicted and measured from a sketch of 3D-CAD Asia-EvaRID model. The new belted pelvis CG displacement was measured for both reference and a stature of Asia-EvaRID model. The $\mathrm{H}$-point of the stature was at pelvis according to chest scale configurations.

The predicted coordinates under oblique crash for the head in the new head CG and the head deflection when belted were calculated from a stature of Asia-EvaRID model and shown in the direction tested as enumerated in TABLEs 4 and 5 , respectively.

TABLE 4

HEAD COORDINATES FOR THE ASIA-EVARID MODEL FASTENED SEAT BELT AND THE DIRECTIONS OF FORCE IN THE ANGULAR TEST DURING LEFT SIDE OBLIQUE IMPACT

\begin{tabular}{lll}
\hline \hline & $\mathrm{K}_{z}(\mathrm{~mm})$ & Direction (degree) \\
\hline $\begin{array}{l}\text { New Head CG Coor- } \\
\text { dinates }\left(180.00_{i}^{1111},\right.\end{array}$ & Head Deflection & Head Deflection \\
$\left.270.00_{j}^{1111}, \mathrm{k}_{z}\right)$ & $\left(-71.75_{i}, 313.36_{j}\right.$, & \\
& $\left.\mathrm{k}_{z}\right)$ & \\
\hline $188.00^{1111}$ & -193.98 & 21.420 \\
150.40 & -155.18 & 17.136 \\
112.80 & -116.39 & 12.852 \\
75.20 & -77.59 & 8.568 \\
37.60 & -38.80 & 4.284 \\
0 & 0 & 0 \\
\hline \hline
\end{tabular}

Fig. 4 shows the angular displacement by force acting on the head and chest affected by accident of car-to-car crash, and analytical theory design of humans affects to the car seat and backrest. In terms of angular displacements for 
unfastened seat belt, the left side frontal oblique impact was also examined using a stature of Asia-EvaRID. The angular calculation by the reference of SB Scenario data [8] was approximated at $0^{\circ}$ to $15^{\circ}$ of the new head and chest CGs; the directional test is enumerated in TABLEs 6 and 7, respectively.

TABLE 5

CHEST COORDINATES FOR THE ASIA-EVARID MODEL FASTENED SEAT BELT AND THE DIRECTIONS OF FORCE IN THE ANGULAR TEST DURING LEFT SIDE OBLIQUE IMPACT

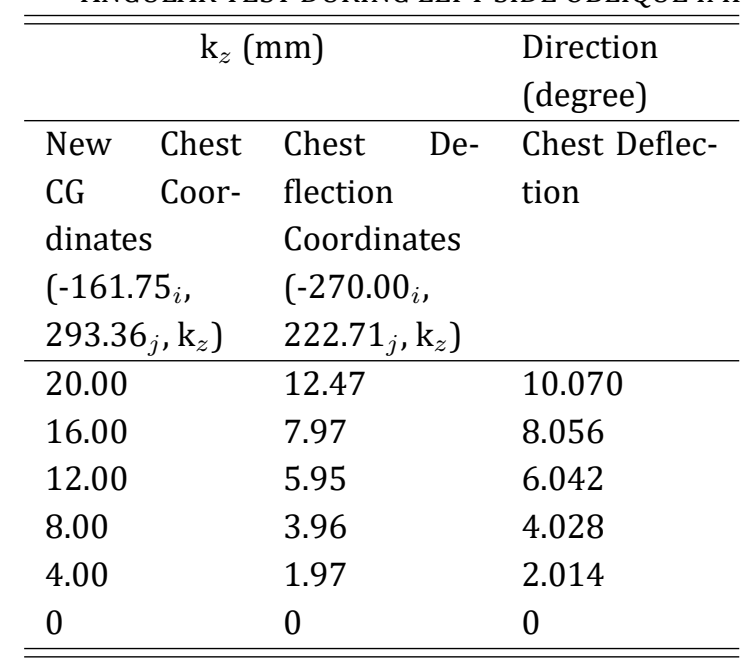

TABLE 6

HEAD COORDINATES FOR THE ASIA-EVARID MODEL UNFASTENED SEAT BELT AND THE DIRECTIONS OF FORCE IN THE ANGULAR TEST DURING LEFT SIDE OBLIQUE IMPACT

\begin{tabular}{lll}
\hline \hline \multicolumn{2}{c}{$\mathrm{k}_{z}(\mathrm{~mm})$} & $\begin{array}{l}\text { Direction } \\
\text { (degree) }\end{array}$ \\
\hline $\begin{array}{lll}\text { New Chest } \\
\text { CG Chest }\end{array}$ De- & $\begin{array}{l}\text { Chest Deflec- } \\
\text { tion }\end{array}$ \\
dinates & $\begin{array}{l}\text { Clection } \\
\text { Coordinates }\end{array}$ \\
$\left(540.00_{i}^{[} 8\right]$, & $\left(-361.44_{i}, 413.03_{j}\right.$, \\
$\left.220.00_{j}^{[} 8\right]$, & $\left.\mathrm{k}_{z}\right)$ & \\
$\left.\mathrm{k}_{z}\right)$ & & $15^{*}$ \\
\hline 380.89 & 116.60 & 12 \\
304.712 & 93.28 & 9 \\
228.534 & 69.96 & 6 \\
152.35 & 46.64 & 3 \\
76.17 & 23.32 & 0 \\
0 & 0 & \\
\hline \hline
\end{tabular}

TABLE 7

CHEST COORDINATES FOR THE ASIA-EVARID MODEL UNFASTENED SEAT BELT AND THE DIRECTIONS OF FORCE IN THE ANGULAR TEST DURING LEFT SIDE OBLIQUE IMPACT

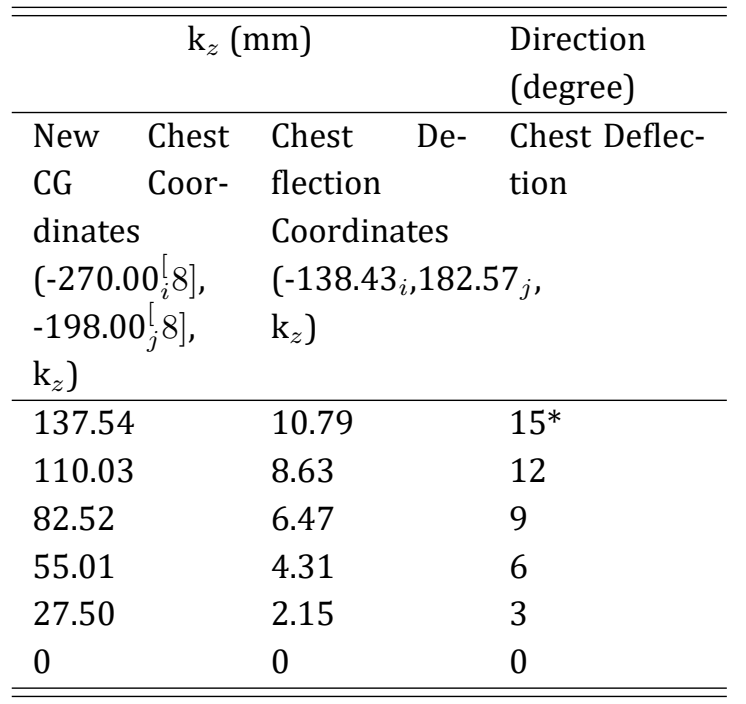

In Table 6 and 7, the head and chest deformations from the crash were in the $\mathrm{x}-, \mathrm{y}$ - and $\mathrm{z}$-axis directions. The head and chest deflection coordinates and directions were obtained from the data in Tables 3 and 4, a stature of dummy with SUVs seat structure in the $\mathrm{x}-, \mathrm{y}$ - and $\mathrm{z}$-axis displacements. The angular displacements by side force for the head and chest are shown in Fig. 5.

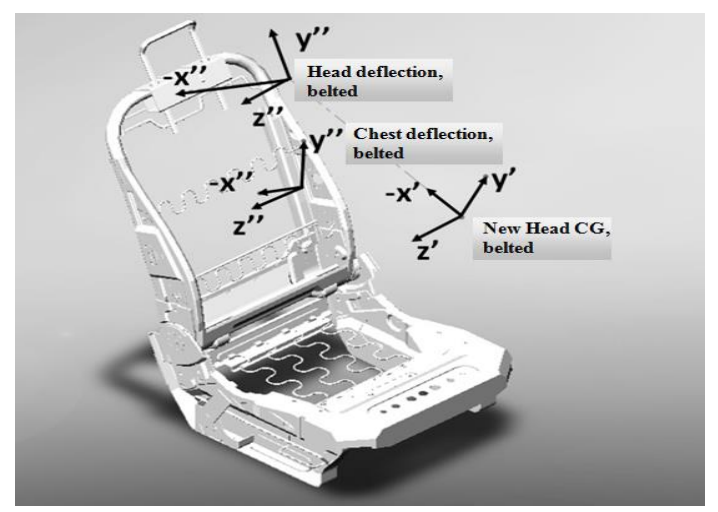

Fig. 4. The 3D seat structure and Asia-EvaRID model: The CG direction for fastened seat belt during left side force

For the right side oblique impact, the new head and chest CGs were simulated for fastened and unfastened seat belts. These generate angular displacements by force under a stature of Asia-EvaRID model. In addition, the new CGs of head and chest were also measured for both the SB Scenario [10] reference and a stature scale configurations. 
The data from a real test by [10] were the following characteristics of the 2D ( $\mathrm{x}, \mathrm{y})$ seating displacements. In this work, the approximated tests are up to $+5 \%$ in degrees of the new head and chest CGs in the specified crash directions.

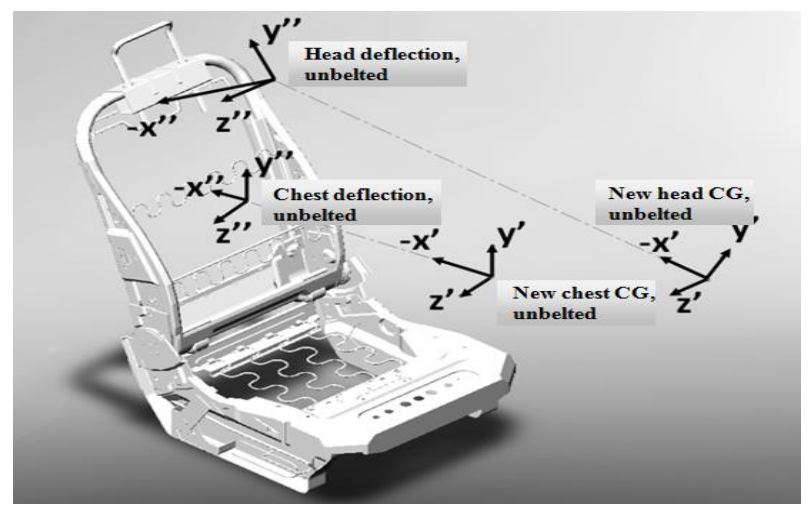

Fig. 5. The 3D seat structure and Asia-EvaRID model: The CG direction for unfastened seat belt during left side force

For the right side oblique crash when unbelted, the displacements were approximated as the same with those of the left side oblique crash with the same coordination.

\section{SIMULATION}

The SUV seat structure in 3D CAD model was analyzed for stress intensity factors in the cases of fastened and unfastened seat belt under the oblique frontal crash $\left(0-15^{\circ}\right)$ with loading conditions: different dummy deformation in left and right side impacts and acceleration, using Finite Element Method (FEM) simulation. The preliminary FEM computational results were previously revealed in [5] that the model approach could be used to obtain accurate stress distribution factors and deformation effect for crash damage or failure structure under certain load test conditions.

The seat model was analyzed using an explicit dynamic simulation and ANSYS software; the conditions are impact angle, impact speed, and test device in both right and left sides. In addition, the analysis employs an explicit dynamic simulation during the real frontal impact and includes a direct contact of Asia-EvaRID model with backrest. The tests by simulation were conforming to the industrial standards and ECE standards in particular. The dummy for the oblique frontal crash was analyzed for head and chest displacements, in left side shown in Table 8 to 11, respectively.
TABLE 8

FORCE AT SPEED ON HEAD DEFLECTION FOR FASTENED AND UNFASTENED SEAT BELT DURING OBLIQUE LEFT SIDE

IMPACT

\begin{tabular}{lllll}
\hline \hline Head Deflection & Direction (degree) & \multicolumn{3}{c}{ Force $(\mathrm{N})$} \\
\hline Belted & & $60 \mathrm{~km} / \mathrm{h}$ & $80 \mathrm{~km} / \mathrm{h}$ & $100 \mathrm{~km} / \mathrm{h}$ \\
Unbelted & 21.42 & $4,101.55$ & $4,101.55$ & $5,273.42$ \\
Belted & 15.00 & $4,103.75$ & $5,319.68$ & $5,714.85$ \\
Unbelted & 17.14 & $3,007.34$ & $4,210.28$ & $5,413.22$ \\
Belted & 12.00 & $4,155.67$ & $5,386.99$ & $5,787.16$ \\
Unbelted & 12.80 & $3,068.21$ & $4,295.49$ & $5,522.77$ \\
Belted & 9.00 & $4,196.21$ & $5,439.53$ & $5,843.61$ \\
Unbelted & 8.57 & $3,111.93$ & $4,356.70$ & $5,601.47$ \\
Belted & 6.00 & $4,225.24$ & $5,477.16$ & $5,884.04$ \\
Unbelted & 4.28 & $3,138.26$ & $4,393.56$ & $5,648.86$ \\
Belted & 0 & $4,242.69$ & $5,499.79$ & $5,908.34$ \\
Unbelted & 0 & $3,147.05$ & $4,405.87$ & $5,664.69$ \\
\hline \hline
\end{tabular}

TABLE 9

ACCELERATION AT SPEED ON HEAD DEFLECTION FOR FASTENED AND UNFASTENED SEAT BELT DURING OBLIQUE LEFT SIDE IMPACT

\begin{tabular}{lllll}
\hline \hline Head Deflection & Direction (degree) & \multicolumn{3}{c}{ Acceleration ('g) } \\
\hline Belted & & $60 \mathrm{~km} / \mathrm{h}$ & $80 \mathrm{~km} / \mathrm{h}$ & $100 \mathrm{~km} / \mathrm{h}$ \\
\hline \multirow{2}{*}{ Unbelted } & $\begin{array}{l}15 \text { degree* }^{*} \\
(64.0 \mathrm{~g})^{[3],[4]}\end{array}$ & $80.0 \mathrm{~g}$ & $112.0 \mathrm{~g}$ & $144.0 \mathrm{~g}$ \\
& $\begin{array}{l}40 \% \text { overlap* }^{*} \\
(60.0 \mathrm{~g})^{[3],[4]}\end{array}$ & $108.0 \mathrm{~g}$ & $140.0 \mathrm{~g}$ & $151.4 \mathrm{~g}$ \\
\hline \hline
\end{tabular}

TABLE 10

FORCE AT SPEED ON CHEST DEFLECTION FOR FASTENED AND UNFASTENED SEAT BELT DURING OBLIQUE LEFT SIDE IMPACT

\begin{tabular}{lllll}
\hline \hline Chest Deflection & Direction (degree) & \multicolumn{3}{c}{ Force $(\mathrm{N})$} \\
\hline & & $60 \mathrm{~km} / \mathrm{h}$ & $80 \mathrm{~km} / \mathrm{h}$ & $100 \mathrm{~km} / \mathrm{h}$ \\
\hline Belted & 10.07 & $9,905.73$ & $11,503.43$ & $13,101.13$ \\
Unbelted & 15.00 & $14,106.64$ & $15,674.05$ & $20,376.30$ \\
Belted & 8.06 & $9,961.44$ & $11,568.12$ & $13,174.80$ \\
Unbelted & 12.00 & $14,285.13$ & $15,872.37$ & $20,634.08$ \\
Belted & 6.04 & $10,004.83$ & $11,618.51$ & $13,232.20$ \\
Unbelted & 9.00 & $14,424.47$ & $16,027.18$ & $20,835.34$ \\
Belted & 4.03 & $10,035.87$ & $11,654.56$ & $13,273.24$ \\
Unbelted & 6.00 & $14,524.27$ & $16,138.07$ & $20,979.50$ \\
Belted & 2.01 & $10,054.50$ & $11,676.20$ & $13,297.89$ \\
Unbelted & 3.00 & $14,584.25$ & $16,204.73$ & $21,066.15$ \\
Belted & 0 & $10,060.72$ & $11,683.42$ & $13,306.11$ \\
Unbelted & 0 & $14,604.27$ & $16,226.97$ & $21,095.06$ \\
\hline \hline
\end{tabular}


TABLE 11

ACCELERATION AT SPEED ON CHEST DEFLECTION FOR FASTENED AND UNFASTENED SEAT BELT DURING OBLIQUE LEFT SIDE IMPACT

\begin{tabular}{lllll}
\hline \hline Chest Deflection & Direction (degree) & \multicolumn{3}{c}{ Acceleration ('g) } \\
\hline & & $60 \mathrm{~km} / \mathrm{h}$ & $80 \mathrm{~km} / \mathrm{h}$ & $100 \mathrm{~km} / \mathrm{h}$ \\
\hline Belted & $\begin{array}{l}15 \text { degree* }^{*} \\
(39.0 \mathrm{~g})^{[3],[4]}\end{array}$ & $46.5 \mathrm{~g}$ & $54.0 \mathrm{~g}$ & $61.5 \mathrm{~g}$ \\
Unbelted & $\begin{array}{l}40 \% \text { overlap* }^{*} \\
(57.8 \mathrm{~g})^{[3],[4]}\end{array}$ & $82.5 \mathrm{~g}$ & $90.0 \mathrm{~g}$ & $97.5 \mathrm{~g}$ \\
& & & \\
\hline \hline
\end{tabular}

Those for the right side oblique crash is shown in Table 12 for impact speed analysis during fastened seat belt. The impact speed derived force generated head, and chest deflections by right side impact for unfastened seat belt were approximated and predicted, up to $+5 \%$ in degrees of those when belted, and are shown for examples in Table 12.

TABLE 12

FORCE AT SPEED ON HEAD AND CHEST DEFLECTIONS FOR FASTENED SEAT BELT DURING OBLIQUE RIGHT SIDE IMPACT

\begin{tabular}{llll}
\hline \hline Deflection & \multicolumn{3}{c}{ Force $(\mathrm{N})$} \\
\hline Head & $3,198.45$ & $4,477.83$ & $5,757.21$ \\
Chest & $10,878.88$ & $12,633.54$ & $14,388.20$ \\
Head & $3,292.46$ & $4,609.44$ & $5,926.42$ \\
Chest & $10,946.41$ & $12,711.95$ & $14,477.50$ \\
Head & $3,366.18$ & $4,712.65$ & $6,059.12$ \\
Chest & $10,999.02$ & $12,773.06$ & $14,547.09$ \\
Head & $3,419.17$ & $4,786.83$ & $6,154.50$ \\
Chest & $11,036.65$ & $12,816.76$ & $14,596.86$ \\
Head & $3,448.59$ & $4,828.03$ & $6,207.46$ \\
Chest & $11,059.25$ & $12,843.00$ & $14,626.76$ \\
\hline \hline
\end{tabular}

\section{RESULTS AND DISCUSSION}

The explicit dynamic simulation and ANSYS software analyses were accomplished during the frontal oblique impact and direct contact of the male Asia-EvaRID model with the backrest. Under the simulation test conforming to industry standards, the test conditions are impact angle, the direction of a crash, and impact speed[14] and [15]. The seat structure parts of the backrest relative to the sled were measured in the displacement of deformation with a minimum interval time of the accident, for the velocity ranging from $60 \mathrm{~km} / \mathrm{h}$ to $100 \mathrm{~km} / \mathrm{h}$.

A. Asia-EvaRID Model Evaluation in Oblique Left Side Im-

ISSN: $2414-4592$

DOI: $10.20474 /$ jater-3.3.2 pact

The Asia-EvaRID model analysis includes maximum deformation in $\mathrm{x}$-axis on peak time and maximum stress distribution of each case with the results shown in Fig. 6 and 7, respectively for the oblique left side impact for both fastened and unfastened cases.

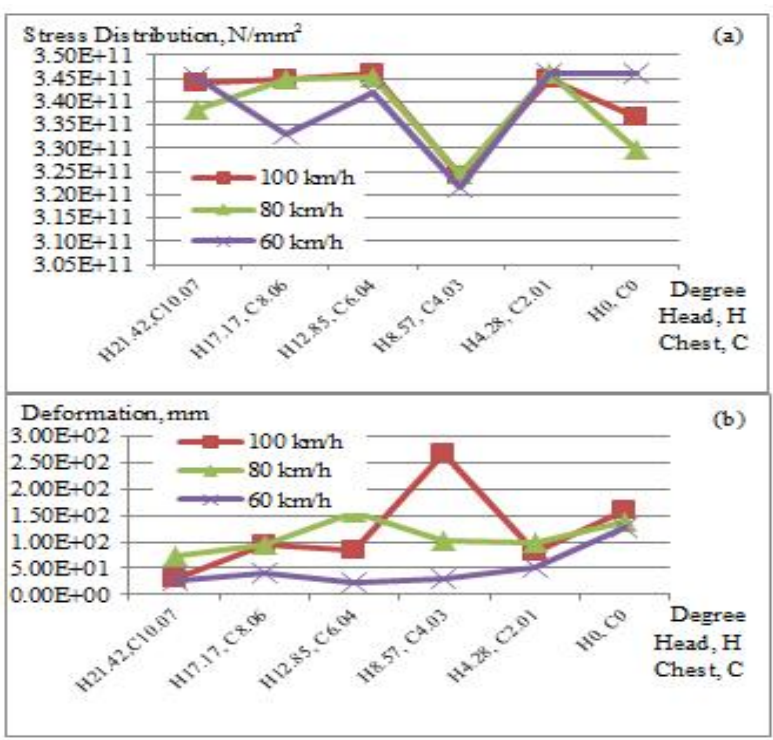

Fig. 6. (a) Maximum stress and (b) Maximum deformation of a male Asia-EvaRID dummy by oblique left side impact during fastened seat belt

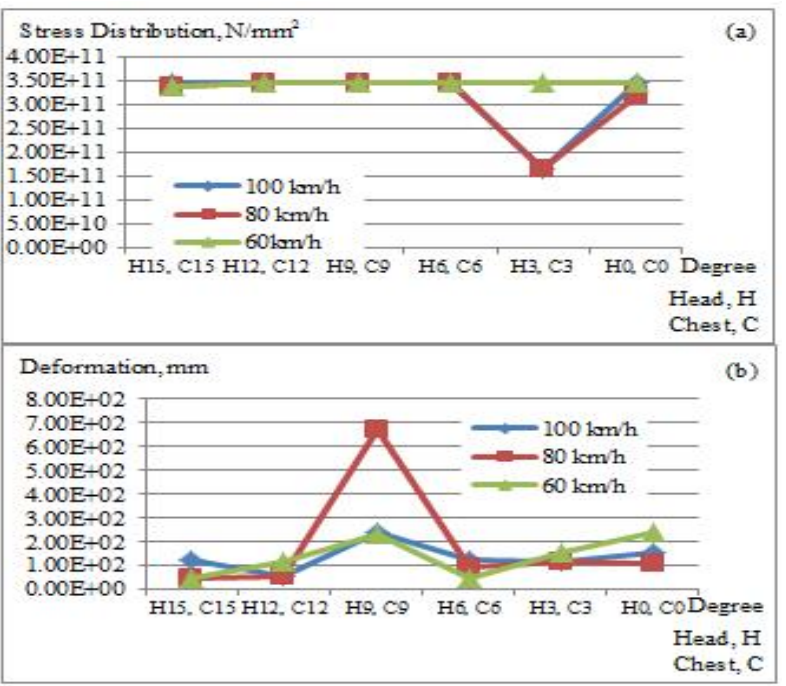

Fig. 7 . (a) Maximum stress and (b) Maximum deformation of a male Asia-EvaRID dummy by oblique left side impact during unfastened seat belt 


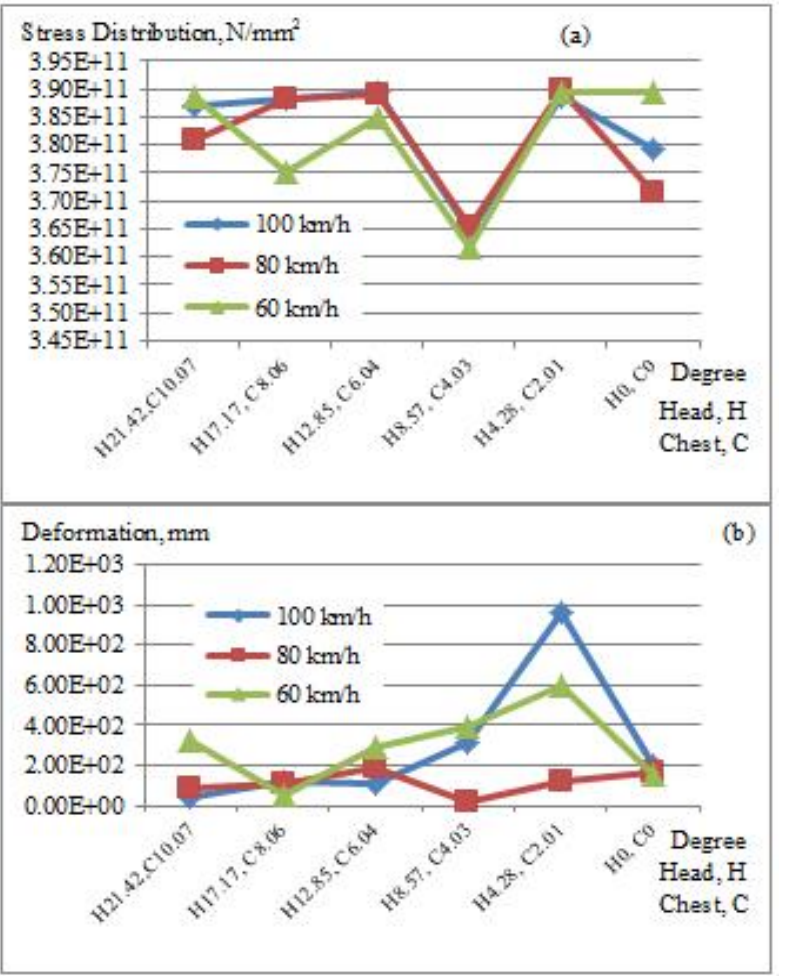

Fig. 8 . (a) Maximum stress and (b) Maximum deformation of a male Asia-EvaRID dummy by oblique right side impact during fastened seat belt

Based on the results shown in Figs. 6 and 7, the fastened seatbelt case generated the maximum stress by $346.14 \mathrm{MPa}$ and structure deformation by $101.77 \mathrm{~mm}$, in the direction $8.57^{\circ}$ at the head and $4.03^{\circ}$ at the chest, with 0.01078 second peak time $(80 \mathrm{~km} / \mathrm{h})$. Meanwhile, the unfastened seat belt case generated the maximum stress by $346.12 \mathrm{MPa}$ and structure deformation by $674.85 \mathrm{~mm}$, in the direction $9^{\circ}$ with 0.06748 second peak time $(100$ $\mathrm{km} / \mathrm{h}$ ).

\section{B. Asia-EvaRID Model Evaluation in Oblique Right Side Impact}

The results depicted in Fig. 8 are for the maximum deformation in the $\mathrm{x}$-axis and maximum stress distribution of Asia-EvaRID model evaluation in oblique right side impact for the fastened seat belt case. Their displacements were approximated in the same approach as previously mentioned.

The fastened Asia-EvaRID model generated the maximum stress by $389.73 \mathrm{MPa}$ and structure deformation by $961.36 \mathrm{~mm}$, in the direction $3^{\circ}$ with 0.04687 second peak time $(80 \mathrm{~km} / \mathrm{h})$.

\section{Research Survey}

The simulation results of the Asia-EvaRID Model are shown in Table 13 in comparison with other models: "the BioRIDII model [12]" and "the ABAQUS model [13]". Those from the literature were appeared to deform by a crash between 122 and $164 \mathrm{~mm}$ at $7 \mathrm{~m} / \mathrm{s}$ velocity. Meanwhile, from this work, the Asia-EvaRID model appeared to deform the backrest ranging from 111.64 to $152.00 \mathrm{~mm}$ at $16.67 \mathrm{~m} / \mathrm{s}$ velocity. Although the seat structures as the models for deformation prediction were different in design and strength of materials used, deformation behavior is, however, comparable to each other but different in values.

TABLE 13

RESULT COMPARISON TO OTHER RESEARCH ON ASIA-EVARID MODEL

\begin{tabular}{|c|c|c|c|c|c|c|c|}
\hline Seat & Model & Reference Data & Impact of Mass $(\mathrm{kg})$ & $\begin{array}{l}\text { Velocity }(\mathrm{m} / \mathrm{s}) \\
\end{array}$ & Time (s) & Peak time (s) & Backrest Deformation (mm) \\
\hline A & BioRID II & 605-Test Result t12] $^{12]}$ & between 100 & $7^{7^{12]}}$ & N.A. & $0.129^{[12]}$ & $164^{[12]}$ \\
\hline B & ABAQQUS & 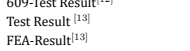 & $\begin{array}{l}168^{122} \\
100^{[13]}\end{array}$ & $7^{[13]}$ & $0.916^{[13]}$ & $\begin{array}{l}0.033 \\
\text { Approx. }\end{array}$ & $122[13]$ \\
\hline c & Asia Eva-RID & $\begin{array}{l}\text { Oblique left, belted } \\
\text { oblique left, unbelted } \\
\text { oblique right, belted, unbelted }\end{array}$ & 100 & 16.67 & 0.873 & $\begin{array}{l}0.067 \\
0.002\end{array}$ & $\begin{array}{l}137.28 \\
111.64 \\
0.002152 .00\end{array}$ \\
\hline
\end{tabular}

\section{CONCLUSION}

The SUV seat structure was under frontal overlap crash at the velocity ranging from $60 \mathrm{~km} / \mathrm{h}$ to $100 \mathrm{~km} / \mathrm{h}$ with standard references of male Asian stature using EvaRID and Bio-RID models under the backrest locked, and derived by the EvaRID model. The seat simulation model was analyzed in the conditions of impact angle in right and left side crash $\left(0-15^{\circ}\right)$ and speed at 0.873 second collision of vehicle resulting in serious injuries. The predicted results were compared in the cases of fastened and unfastened seatbelts. The dummy had the pelvis CG reference point and the other CGs vary by stature of the dummy.

The analysis shows the stress distribution and the displacement of deformation with a minimum interval time of accident that requires improvement in design to support such a harsh condition of the SUV's passenger usages at present. The unfastened seatbelt case displayed the highest deformation structure and highest distribution stress than those of the fastened seatbelt case.

The analysis of Asia-EvaRID tests for fastened seatbelt has shown the maximum stress distributions and structure deformation in the oblique right side impact at $3^{\circ}$ for head and chest at 0.04687 second peak time. For the crash in both sides, the fastened seatbelt cases resulted in higher tensile strength than the unfastened seatbelt cases. In com- 
parison, the Asia-EvaRID in the left side impacts the structure deformed to a greater extent than that of the right side impact. This ongoing work precedes the upcoming determination of standard model effects and dynamic tests on seat structure. This presumes a provision of a deeper understanding of the potential benefits of different models, failure modes, side effects, and seatbelt conditions.

\section{ACKNOWLEDGEMENT}

Kasetsart University Faculty of Engineering at Sriracha is acknowledged for financial support to this project.

\section{REFERENCES}

[1] Economic Commission for Europe of the United Nations (UN/ECE), "Uniform provisions concerning the approval of vehicles with regard to the seats, their anchorages and any head restraints," Geneva, Switzerland, 2002.

[2] H. Asada and K. Nawata, "Study on static and quasidynamic evaluation method for assessing whiplashassociated disorders in rear impact," [Online]. Available at: https://goo.gl/UYggGR

[3] T. William, C. Hampton, L. Sheldon, S. Stephen and R. James, "Updated review of potential test procedures for FMVSS," National Highway Traffic Safety Administration (NHTSA), Washington, DC., WA, 1999.

[4] J. Saunders, D. Parent and E. Ames, "NHTSA oblique crash test results: Vehicle performance and occupant injury risk assessment in vehicles with small overlap countermeasures," National Highway Traffic Safety Administration (NHTSA), Washington, DC., WA, 2015.

[5] S. Wittayapiyanon and S. Chuepeng, "Explicit dynamic simulation of frontal impact in commercial van seat structures," in The 2nd International Conference on Engineering Science and Innovative Technology (ESIT 2016), Phuket, Thailand, 2016.

[6] Indian Automobile Industry Standards (AIS), "AIS-097 Procedure for determining the H-Point and the Torso angle for 50th percentile adult male in seating positions of motor vehicles," Automotive Industry Standard, Government of India, New Delhi, India, 2007.

[7] World Health Organization (WHO), "The Asia-Pacific perspective redefining obesity and its treatment," The
International Obesity Task Force, World Health Organization (WHO), Geneva, Switzerland, 2000,

[8] S. Ejima, D. Ito, J. Antona, Y. Sukegawa and H. Ito, "Preimpact braking influence on the standard seat-belted and motorized seat-belted occupants in frontal collisions based on anthropometric test dummy," in International Research Council on Biomechanics of Injury Conference (IRCOBI), Krakow, Poland, 2011.

[9] B. Pipkorn, J. Lopez-Valdes, O. Juste-Lorente, M. Maza and C. Sunnevång, "Study of the Kinematics of the THOR dummy in nearside oblique impacts," in International Research Council on Biomechanics of Injury Conference (IRCOBI), Malaga, Spain, 2016.

[10] M. Katagiri, J. Zhao, J. Kerrigan, R. Kent and J. Forman, "Comparison of whole-body Kinematic behaviour of the GHBMC occupant model to PMHS in far-side sled test," in International Research Council on Biomechanics of Injury Conference (IRCOBI), Malaga, Spain, 2016.

[11] Jason L. Forman, J. Lopez-Valdes, D. Nate, W. Kent, T. Hiromasa and K. Higuchi, "An inflatable belt system in the rear seat occupant environment: investigating feasibility and benefit in frontal impact sled tests with a 50th percentile male ATD," in 54th Annual Scientific Conference, Annals of Advances in Automotive Medicine, Las Vegas, NV, 2010.

[12] T. Olssona, N. Truedssona, A. Lindera, A. Morrisaand B. Fildesa, "Evaluation of seat protection in low to medium severity rear impacts by means of the BioRID II and double peak crash pulses," in Australasian Road Safety Research, Policing and Education Conference (ARSRPE), Victoria, Australia, 2001.

[13] H. Hartmann, M. Socko and R. Hanley, "Using a Drop Tower test to Dynamically Validate an ABAQUS model of an Automotive Seat for Side Impact Crash Simulation," in ABAQUS Users' Conference, Paris, France, 2007.

[14] Sugiyatno, I. Djunaedi and N. A. Mahardiono, "Modelling and simulation of hybrid control system in solar cellbattery-super capacitor," International Journal of Technology and Engineering Studies, Vol. 1, no. 3, pp. 74-80, 2015. DOI: $10.20469 /$ ijtes.40002-3

[15] Bahrudin, H. S. Alam and T. Haiyunnisa, "Computational fluid dynamic simulation of pipeline irrigation system based on ansys," International Journal of Technology and Engineering Studies, vol. 2, no. 6, pp. 189-193, 2016. DOI: $10.20469 /$ ijtes.2.40005-6 